\title{
Proceedings of the 2nd ASIS SIG/CR Classification Research Workshop \\ (Distributed to registrants October, 1991)
}

\author{
October 27, 1991
}

\author{
Held at the 54th ASIS Annual Meeting \\ Washington, D.C. \\ October 27-31, 1991
}

Editors and workshop co-chairs:

Barbara H. Kwasnik

Raya Fidel

\author{
Printed and distributed by the \\ American Society for Information Science \\ Special Interest Group / Classification Research
}


The opinions expressed by contributors to this publication do not necessarily reflect the position or official policy of the American Society for Information Science

Copyright (C1991 by American Society for Information Science 8720 Georgia Avenue, Suite 501, Silver Spring, MD 20910-3602 Phone: (301) 495-0900

Fax: (301) 495-0810 


\section{Preface}

\section{General Comments}

These Proceedings are a working copy of the papers and personal statements of participants of the 2nd ASIS SIG/CR Workshop on Classification Research to be held at the ASIS Annual Meeting on Sunday, October 27th, 1991, in Washington, D.C. They are being distributed early to participants only so that they have a chance to review in advance the contributions and descriptions of those who will be in attendance. As such, the papers are not in their final versions, and authors will have the opportunity to revise and edit their papers and descriptions. The Proceedings will then be published as an ASIS monograph by Learned Information, Inc., under the title Advances in Classification Research, and will be available for purchase in 1992.

We were gratified by the quality of the papers and diversity of topic areas submitted to this year's workshop. By May we had received over thirty position papers and they kept coming even after that. Our experience from last year was that people really liked the diversity and excitement of a workshop in which a wide variety of disciplines and areas were included, and judging by the comments on the evaluation forms, participants were very pleased in general with how it all came together. We received many favorable comments afterwards as well. The only complaint was that it was overwhelming in terms of the number of presentations in one day (twenty), especially since the workshop brought together researchers and practitioners from many fields, each with its own special body of knowledge and vocabulary. Therefore, this year, we have changed our policy and limited the number of presentations, while at the same time, continued to cast a wide net in terms of subject areas. We hope that this will leave more time for discussion and questions and even further enhance the main purpose of the workshop, which is to bring together people from many areas to exchange ideas about the very lively area of classification research. Maybe in the future we will decide to focus more specifically on some area, but for now, we feel that the more general exchange is fruitful and interesting.

It was very difficult to choose the fifteen papers selected for presentation. All the submissions were interesting, provocative, and we could have included many more. We aimed for broad coverage of topics and application areas, and we tried to include those that would stimulate discussion and further exploration of the ideas introduced by the presenters.

\section{Organization of These Proceedings}

The papers that will be presented at the Workshop are arranged in alphabetical order by the last name of the first author. Following these papers are the Personal Statements of all the Workshop participants who submitted such a statement as of September 22, 1991. These are also arranged in alphabetical order. We did not specify what should go into these personal statements, and they are essentially unedited. The List of Participants follows the Personal Statements and is continually undergoing changes. A final list will be distributed at the Workshop. An agenda will be mailed out under separate cover as soon as it is finalized.

We are sorry that we didn't have enough time to index these Proceedings, but will gratefully accept any offers of help in doing so for the published version. 


\section{Acknowledgments}

We would like to thank all the participants for their submissions. The authors of the papers to be presented were most cooperative and gracious in working with us on edits and clarifications. Our aim was to make the papers understandable to a wide audience, and we acknowledge their patience with our questions and suggestions.

We wish to thank ASIS officials and staff, who have subsidized this Workshop, have nurtured it along, and have been most enthusiastic about all aspects, but in particular, have facilitated the preparation and distribution of these Proceedings. Our Schools, the Graduate School of Library and Information Science at the University of Washington, and the School of Information Studies at Syracuse University have also facilitated our efforts at organizing this Workshop. Throughout the process, Susanne Humphrey (co-editor of last year's Proceedings) has offered guidance in many ways, for which we express our deep gratitude. A special thank you goes to Bill Murray, an MLS student at the Syracuse School of Information Studies, for his many hours of formatting and preparing the manuscript for these Proceedings.

Finally, we wish to acknowledge the inventors of the fax machine and electronic mail, without which our work in coordinating this effort would have been doubled.

B.K.F. and R.F.

Comments or questions may be sent to the editors as follows:

Barbara H. Kwasnik

School of Information Studies

4-206 Center for Science and Technology

Syracuse University

Syracuse, NY 13244-4100

Office: (315) 443-2911

Fax: (315) 443-5806

Internet: bkwasnik@suvm.acs.syr.edu

Raya Fidel

Graduate School of Library and Information Science

University of Washington, FM-30

Seattle, WA 98195

Office: (206) 543-1888

Fax: (206) 685-8049

Internet: fidelr@max.u.washington.edu 


\section{Table of Contents}

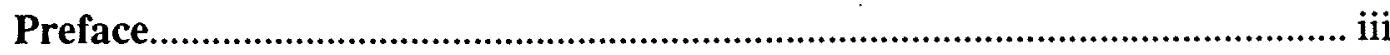

PRESENTED PAPERS

Building End-User Thesauri from Full Text

James D. Anderson and Frederick A. Rowley.................................... 1

Conceptual Clustering in Database Systems

Tarek M. Anwar, Howard W. Beck, and Shamkant B. Navathe........... 11

The Semantic Classification in the Temporal Theory of Psychoanalysis

Antal F. Borbely.

The Classification of Medical Events Using Latent Semantic Analysis

C.G. Chute.

Use and Management of Classification Systems for Knowledge-Based

Indexing

Susanne M. Humphrey

Classification and Categorization: Drawing the Line

Elin K. Jacob.

Applied Cladistics: New Models for Classification and Taxonomy

Research; or How the New York Review of Books Taught Me Everything I

Needed to Know about Taxonomy Research

Arthur McCaffrey.

Toward a Relation Hierarchy for Information Retrieval

Sung H. Myaeng and Michael L. McHale

Data Structure for an Archival Image System: A Proposal

Elizabeth Carley Oddy.

Terminology Maintenance for Corporate Information Retrieval Marlene Rockmore.

Interface Issues in Providing Access to Databases Using Semantic

Classification Techniques

Philip J. Smith and Bekka Denning.

Beyond Facets: Semantic Roots and Modifiers as Elements of a

Conceptual Morphology

Dagobert Soergel. 
User-Based Methods for Classification Development

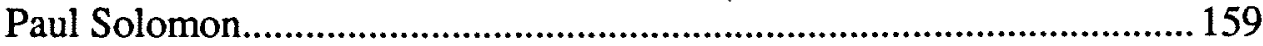

Hypertext Linking as a Model of Expert Indexing

Judith A. Tessier.

Using an Adaptation of Piaget's Operative Logic of Classes for Analyzing

Classification Systems

Raul Sidnei Wazlawick

\section{APPENDICES}

Personal Statements of Participants

(in alphabetical order)

List of Workshop Participants 